\title{
Couple Age Discrepancy and Risk of Intimate Partner Homicide
}

\author{
Noelia Breitman \\ Todd K. Shackelford \\ Florida Atlantic University \\ Davie, $F L$ \\ Carolyn Rebecca Block \\ Illinois Criminal Justice Information Authority \\ Chicago, IL
}

\begin{abstract}
Although national level studies in the United States and Canada find that extreme partner age discrepancy is a risk factor for intimate partner homicide in opposite-sex couples, these studies carry two caveats: They are limited to cohabiting marital or common-law couples and they are not detailed enough to explore alternative explanations for the age discrepancy-homicide risk association. Using the Chicago Homicide Dataset, which includes all homicides that occurred in Chicago from 1965 to 1996, we analyze the 2,577 homicides in which the victim was killed by a current or former legal spouse, commonlaw spouse, or heterosexual boyfriend or girlfriend, and in which the woman was at least 18 years of age. Within each of 14 categories of couple age discrepancy, we estimate the population of intimate heterosexual couples and calculate the population-based risk of homicide. The results replicate national level findings showing that the risk of intimate partner homicide is considerably elevated for couples with a large discrepancy between their ages-where the man is at least 16 years older than the woman or the woman is at least 10 years older than the man. This risk pattern occurs regardless of whether the man or the woman was the homicide offender. We then investigate whether the link between partner age discrepancy and homicide risk is explained by the offender's arrest record. Results show that the higher risk of intimate partner homicide for age discrepant couples is robust, and does not depend on the previous arrest record of the offender. Discussion addresses other possible explanations for the increased risk of partner homicide for age discrepant couples, and the practical implications of these findings.
\end{abstract}

Keywords: intimate partner homicide; age discrepancy; risk factors; arrest record

$\mathrm{M}$ uch research has investigated patterns and predictors of intimate partner homicide (IPH) - defined here as a homicide by a current or former legal spouse, common-law spouse, boyfriend, or girlfriend. Factors reported to affect a couple's risk of IPH include the race and socioeconomic status of the man and the woman, the type of marital union (married or not; cohabiting or not), male sexual proprietariness and jealousy, the length of the relationship, a partner's attempt to terminate the relationship, the presence of stepchildren, alcohol and drug use, and the type and availability of weapon (Block, 1987, 2000a; Block \& Christakos, 1995; Boudouris, 1971; Daly \& 
Wilson, 1988; Mercy \& Saltzman, 1989; Schwartz, 1988; Shackelford, 2000, 2001a, 2001b; Shackelford, Buss, \& Peters, 2000; Wilson \& Daly, 1992, 1994, 1996, Wilson, Daly, \& Wright, 1993; Wilson, Johnson, \& Daly, 1995). In addition to these risk factors, several studies using Canadian and United States national databases have found that IPH risk is higher for cohabiting married or common-law couples with a large difference between the ages of the man and the woman. Daly and Wilson (1988; and see Wilson \& Daly, 1993, 1994; Wilson et al., 1993, 1995) reported that spousal homicide victimization rates in Canada for both men and women increased as the couple's age discrepancy increased. They found this to be true regardless of who was the older party, and for both common-law (nonmarital, cohabiting) marriages and legal marriages. Shackelford (2000, 2001a, 2001b; see also Mercy \& Saltzman, 1989; Shackelford et al., 2000) replicated these results in the United States using a national level database, the Federal Bureau of Investigation's Supplementary Homicide Reports for 1976 through 1994.

An advantage of these national level studies is that they use population-based rates. The results, therefore, can be related directly to practical applications and to interventions focused on reducing the risk of death in intimate relationships. There are several limitations inherent in these studies, however. First, they are based on only two types of heterosexual intimate relationship — cohabiting legal marriage and common-law marriage. This ignores other types of intimate relationship-specifically, ex-spousal, ex-common-law, and current and former boyfriend/girlfriend-that are regarded as intimate partner relationships by the Centers for Disease Control (Saltzman et al., 1999) and the Bureau of Justice Statistics (Rennison \& Welchans, 2001). In addition, it ignores intimate relationships (whether marital, common-law or boyfriend/girlfriend) in which the couple does not live together. These account for a considerable proportion of the population who are in heterosexual intimate relationships, and there is evidence that they carry a higher risk of intimate partner homicide (Paulozzi et al., 2001; Rennison \& Welchans, 2000; Schwartz, 1988; but see Rennison, 2001).

A second limitation of previous studies is that they use databases that do not contain enough detail to identify or even address the mechanisms linking age discrepancy and homicide risk. Such detailed databases do exist, however, and may provide the opportunity to investigate and identify the mechanisms linking age discrepancy and IPH. In Chicago, for example, Block and Christakos (1995) analyzed risk patterns associated with IPH using the Chicago Homicide Dataset, which consists of archived data from 1965 to 1995, and found a number of correlates with age discrepancy. More recently, the Chicago Women's Health Risk Study (Block, 2000a) combined data on lethal and nonlethal intimate partner violence to examine risk factors for death, including age discrepancy.

An avenue by which age discrepancy may operate to increase the likelihood of IPH is suggested by the research of Wu and colleagues (Wu \& Balakrishnan, 1995; Wu \& Hart, 2001). They define age discrepancy as one aspect of couple "heterogeneity," and find that age heterogeneity or difference increases the risk of relationship dissolution (Wu \& Hart, 2001). Specifically, they report that "the hazard rate of dissolution is $199 \%$ higher for women-older unions and 63\% higher for men-older unions than age-homogenous unions" (Wu \& Hart, 2001, p. 19). Hence, one possible explanation for the age discrepancy-IPH link could be that age discrepancy increases the risk of relationship dissolution, which in turn increases the risk of violence and homicide (Campbell, 1992; Johnson, 1996; Wilson \& Daly, 1992, 1993, 1994).

Another candidate for explaining the link between age discrepancy and homicide risk is the previous arrest history of the IPH offender. Daly and Wilson (1988, and see Wilson et al., 1993) suggest that the relationship between age discrepancy and the risk of IPH 
might be explained by an increased likelihood for intimate partner offenders in age-discrepant relationships to be involved in all sorts of crime, not just IPH. Couples with large age discrepancy between the partners are statistically unusual and, therefore, "such couples may be atypical in a number of other respects including attributes or circumstances which increase the risk of conflict and homicide" (Wilson et al., 1993, p. 285). People in age-discrepant relationships may be more likely to have previous criminal records than people in age-similar relationships in which an intimate partner has been killed. This explanation for the increased risk of IPH among age-discrepant couples has not been tested empirically.

The purposes of the current research are, first, to determine whether the finding that age-discrepant couples are at an increased risk of IPH compared to age-similar couples is robust for couples who are in any type of heterosexual relationship, not only cohabiting marital or cohabiting common-law relationships. Thus, the first hypothesis is that the population-based risk of IPH is higher for all heterosexual intimate partner couples when their age discrepancy is large, compared to age-similar couples. If the first hypothesis is supported, we will then test the robustness of the link between age discrepancy and homicide risk, first by determining if the pattern is consistent whether the homicide offender is the man or the woman, and second by determining whether the pattern is consistent regardless of the homicide offender's prior arrest record. Thus, the second hypothesis is that the population-based risk of IPH with a man or woman offender is higher for age-discrepant than for age-similar heterosexual couples, and the third hypothesis is that the association between the couple's age discrepancy and risk of IPH is reduced or eliminated after controlling for the homicide offender's previous arrest record.

\section{METHOD}

\section{Intimate Partner Homicide Data}

The Chicago Homicide Dataset (Block \& Block, 2001) is one of the largest and most detailed datasets on homicide in the United States. It has been collected and maintained for many years by the Illinois Criminal Justice Information Authority, in cooperation with the Crime Analysis Unit of the Chicago Police Department. The current analysis adds preliminary data for 1996, so that the dataset includes information on 24,609 homicides recorded by the Chicago police between 1965 and $1996 .{ }^{1}$ We selected the 2,661 homicides in which the victim and offender were opposite-sex intimate partners (943 husband/wife, 62 ex-husband/ex-wife, 793 common-law husband/wife, 33 ex-common-law husband/wife, 724 boyfriend/girlfriend, and 106 ex-boyfriend/ex-girlfriend). ${ }^{2}$ We excluded 79 homicides (51 woman-victim homicides and 28 woman-offender homicides) in which the woman's age was younger than 18 (leaving 2,582 cases) and an additional five cases in which the age of the woman (two cases) or man (three cases) was not known, leaving 2,577 cases for analysis. Thus, the data analyzed here constitute the universe of heterosexual intimate couples in Chicago, in which one partner killed the other in the years 1965 to 1996, and in which the ages of both partners were known and the woman was at least 18 years old at the time of the homicide. Basic characteristics of the homicides are shown in Table 1.

For the analyses of age discrepancy, we divided the 2,577 couples into 14 categories: one central category (both partners were the same age), seven categories for "man older" (ranging from 1 to 3 years older to more than 20 years older), and six categories for "woman older" (ranging from 1 to 3 years older to more than 15 years older; there were 
TABLE 1. Victim-Offender Characteristics in Heterosexual Intimate Partner Homicides, Chicago 1965-1996: Type of Relationship, Victim's Race/Ethnicity, and Victim's Sex ${ }^{\mathrm{a}}$

\begin{tabular}{|c|c|c|c|c|c|c|c|}
\hline $\begin{array}{l}\text { Victim's Sex and } \\
\text { Racial/Ethnic Group }\end{array}$ & Spouse & $\begin{array}{c}\text { Ex- } \\
\text { Spouse }\end{array}$ & $\begin{array}{c}\text { Common- } \\
\text { Law } \\
\text { Spouse }\end{array}$ & $\begin{array}{c}\text { Ex- } \\
\text { Common- } \\
\text { Law } \\
\text { Spouse }\end{array}$ & $\begin{array}{c}\text { Boy/ } \\
\text { Girl } \\
\text { Friend }\end{array}$ & $\begin{array}{l}\text { Ex- } \\
\text { Boy/ } \\
\text { Girl } \\
\text { Friend }\end{array}$ & Total \\
\hline \multicolumn{8}{|l|}{ Men } \\
\hline White, non-Latino & 44 & 3 & 29 & 0 & 12 & 2 & 90 \\
\hline Black, non-Latino & 377 & 14 & 396 & 11 & 280 & 38 & 1,116 \\
\hline Latino & 14 & 3 & 12 & 0 & 13 & 1 & 43 \\
\hline Asian, Other & 2 & 0 & 3 & 0 & 1 & 0 & 6 \\
\hline Total & 437 & 20 & 440 & 11 & 306 & 41 & 1,255 \\
\hline \multicolumn{8}{|l|}{ Women } \\
\hline White, non-Latina & 157 & 13 & 50 & 4 & 54 & 9 & 287 \\
\hline Black, non-Latina & 296 & 26 & 259 & 15 & 279 & 40 & 915 \\
\hline Latina & 36 & 2 & 32 & 3 & 20 & 5 & 98 \\
\hline Asian, Other & 7 & 1 & 6 & 0 & 6 & 2 & 22 \\
\hline Total & 496 & 42 & 347 & 22 & 359 & 56 & 1,322 \\
\hline
\end{tabular}

a Total $N=2,577$. This table does not include 79 cases in which the woman was age 17 or younger, or 5 cases in which the woman's or man's age was not known.

too few homicides in which the woman was more than 20 years older to analyze that category by itself). Although age discrepancy can be used as a ratio-level metric, it is more accurate to interpret it as a set of culturally driven and defined categories. For example, the category "woman 13 to 15 years older than man" and the category "man 13 to 15 years older than woman" may not have equivalent cultural significance. Because we had no theoretical basis for using any particular age discrepancy categories, and the large $N$ in the Chicago Homicide Dataset allows great flexibility, we used relatively small age ranges, increasing in small increments. These small categories help to ensure that a surge or decline at a specific age discrepancy level will not be obscured by being grouped into a larger category. In addition, assuming that the analysis finds differences in homicide risk along categories of age discrepancy, the small categories will allow the data to reveal more precisely where the increase or decrease lies.

In the present dataset, women's ages range from 18 to 84 years. The average age of women is 34.14 years $(S D=11.3)$, with no significant difference between women who were homicide victims $(34.31 ; S D=11.8)$ and women who were homicide offenders (33.96; $S D=10.8 ; t<1.00, p>.05$ ). Men's ages range from 16 to 90 years. The average age of men is 37.85 years $(S D=12.2)$, with no significant difference between men who were homicide victims $(38.20 ; S D=11.95)$ and men who were homicide offenders $(37.52$; $S D=12.4 ; t<1.00, p>.05)$. The mean age discrepancy between the intimate partners, calculated as the man's age minus the woman's age, is 3.71 years $(S D=9.34)$, and ranges from the woman being 34 years older than the man (she was 82; he was 48) to the man being 51 years older than the woman (she was 29; he was 80 ). The mean age discrepancy is significantly higher $[t(2,575)=2.80, p=.005]$ when the man was the homicide victim (4.22), compared to when the woman was the homicide victim (3.21).

The mean ages of the partners will almost always vary with the couple's age discrepancy. This is an important methodological consideration, because age has been associated with risk of IPH offending (Shackelford, 2000), and because the wife's age is known to 


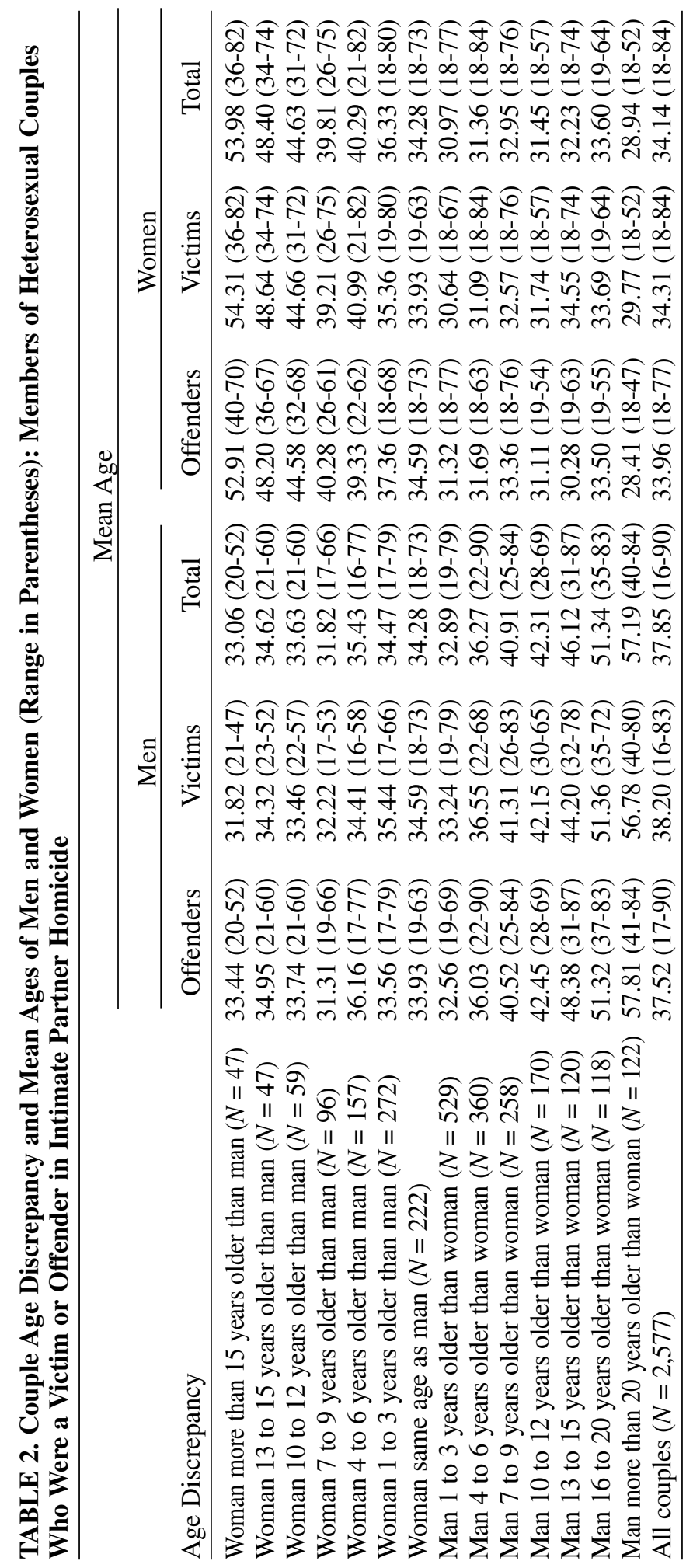


TABLE 3. Relative Age of Victim and Offender by Age Discrepancy, Intimate Partner Homicides in Chicago $(N=\mathbf{2 , 3 5 5})^{\mathrm{a}}$

\begin{tabular}{lccr}
\hline & \multicolumn{3}{c}{ Relative Age of Victim and Offender } \\
\cline { 2 - 4 } Age Discrepancy & Offender Older & Offender Younger & Total \\
\hline Woman more than 15 years older than man & $23.4 \%$ & $76.6 \%$ & 47 \\
Woman 13 to 15 years older than man & $53.2 \%$ & $46.8 \%$ & 47 \\
Woman 10 to 12 years older than man & $40.7 \%$ & $59.3 \%$ & 59 \\
Woman 7 to 9 years older than man & $56.3 \%$ & $43.8 \%$ & 96 \\
Woman 4 to 6 years older than man & $42.0 \%$ & $58.0 \%$ & 157 \\
Woman 1 to 3 years older than man & $48.5 \%$ & $51.5 \%$ & 272 \\
Man 1 to 3 years older than woman & $51.0 \%$ & $49.0 \%$ & 529 \\
Man 4 to 6 years older than woman & $53.9 \%$ & $46.1 \%$ & 360 \\
Man 7 to 9 years older than woman & $51.2 \%$ & $48.8 \%$ & 258 \\
Man 10 to 12 years older than woman & $53.5 \%$ & $46.5 \%$ & 170 \\
Man 13 to 15 years older than woman & $45.8 \%$ & $54.2 \%$ & 120 \\
Man 16 to 20 years older than woman & $52.5 \%$ & $47.5 \%$ & 118 \\
Man more than 20 years older than woman & $39.3 \%$ & $60.7 \%$ & 122 \\
All couples & $49.4 \%$ & $50.6 \%$ & 2,355 \\
\hline
\end{tabular}

${ }^{\text {aThe }} 222$ cases where the victim and offender were the same age have been excluded from this table.

be associated with her risk of homicide victimization (Dumas \& Perón, 1992; Mercy \& Saltzman, 1989; Shackelford et al., 2000; Wilson et al., 1995). In the national level Canadian Violence Against Women survey (Johnson, 1996), both victim's and partner's ages predict violent victimization by a current spouse, with the risk at age group 18 to 24 years three times higher than the next highest age group. In a review of the research, Wilson and Daly (1992) confirm this, finding independent age effects for victim and offender. However, in the present study, there is a wide variation in age range at every age discrepancy level, whether the offender is the man or the woman (Table 2). For example, the mean age of women who are at least 15 years older than the man is 54, but their ages range from 36 to 82 ; the mean age of men when the woman is at least 15 years older is 33 , but the range is 20 to 52 .

Previous studies have also reported that reproductive age women (women who are less than 45 years old) are overrepresented among offenders and victims of spousal homicides (Shackelford, 2000; Shackelford et al., 2000). An analysis of the present data confirms these results: the woman was less than 45 years in $82.9 \%$ of women-offender IPHs, and in $82.8 \%$ of women-victim IPHs. Further, the offender in age-discrepant relationships is not necessarily the younger of the two partners (Table 3). Overall, the offender is older than the victim in one-half of the homicides (49.4\%). There are only two age discrepancy categories in which the offender is younger in at least $60 \%$ of the homicides-when the woman is more than 15 years older than the man (11 female-offender homicides and 36 male-offender homicides), and when the man is more than 20 years older than the woman (74 female-offender homicides and 48 male-offender homicides).

Although there is no significant difference in mean age discrepancy across types of relationship for all 2,577 couples, there are significant differences for the 1,255 homicides where the woman killed the man (Table 4). The difference involves current versus former status, not spouse versus common-law versus boyfriend/girlfriend. The difference in mean age discrepancy between current and former relationships is significant for homicides 
TABLE 4. Mean Couple Age Discrepancy (Man's Age Minus Woman's Age) by Relationship

\begin{tabular}{|c|c|c|c|c|c|c|}
\hline \multirow[b]{2}{*}{$\begin{array}{l}\text { Relationship Type and } \\
\text { Current or Former }\end{array}$} & \multicolumn{2}{|c|}{ Man Victim ${ }^{\mathrm{a}}$} & \multicolumn{2}{|c|}{ Woman Victim ${ }^{\mathrm{a}}$} & \multicolumn{2}{|c|}{ Total } \\
\hline & $\begin{array}{c}M \text { Age } \\
\text { Discrepancy }\end{array}$ & $N$ & $\begin{array}{c}M \text { Age } \\
\text { Discrepancy }\end{array}$ & $N$ & $\begin{array}{c}M \text { Age } \\
\text { Discrepancy }\end{array}$ & у $N$ \\
\hline \multicolumn{7}{|l|}{ Type of relationship } \\
\hline Spouse & 4.57 & 437 & 3.65 & 496 & 4.08 & 933 \\
\hline Ex-spouse & .95 & 20 & 3.45 & 42 & 2.65 & 62 \\
\hline Common-law & 4.13 & 440 & 2.44 & 347 & 3.39 & 787 \\
\hline Ex-common-law & -1.45 & 11 & 6.36 & 22 & 3.76 & 33 \\
\hline Boyfriend/ girlfriend & 4.59 & 306 & 3.02 & 359 & 3.74 & 665 \\
\hline Ex-boyfriend/ ex-girlfrien & ad 2.46 & 41 & 3.91 & 56 & 3.30 & 97 \\
\hline \multicolumn{7}{|l|}{ Current or former } \\
\hline Current & 4.41 & 1,183 & 3.11 & 1,202 & 3.76 & 2,385 \\
\hline Ex or former & 1.44 & 72 & 4.20 & 120 & 3.17 & 192 \\
\hline Total $^{\mathrm{b}}$ & $4.24^{\mathrm{c}}$ & 1,255 & $3.21^{\mathrm{d}}$ & 1,322 & 3.71 & 2,577 \\
\hline
\end{tabular}

${ }^{a}$ The difference in mean age discrepancy between homicides with a man or woman victim is significant for two types of relationship: common-law (4.13 versus $2.44, t(785)=$ $2.332, p=.02)$, and ex-common-law $(-1.45$ versus $6.36, t(31)=-2.357, p=.025)$. The difference in mean age discrepancy between homicides with a man or woman victim is significant for current relationships (4.41 versus 3.11, $t(2383)=3.386, p=.001$ ) and for former relationships (1.44 versus $4.20, t(190)=-2.157, p=.032$ ).

bNone of the differences in mean age discrepancy across types of relationship is significant for total intimate partner homicides. For example, for spouse (4.08) versus exspouse (2.65), $t(993)=1.513, n s$. Also, the difference for current (3.76) versus former (3.71) relationships is not significant, $t(2575)=.841, n s$.

${ }^{\mathrm{c}}$ For homicides with men victims, the difference in mean age discrepancy is significant between spouse and ex-spouse, $t(455)=2.100, p=.036$, boyfriend/girlfriend and exspouse, $t(28.66)=2.376, p=.024$, and spouse and ex-common-law, $t(446)=2.612, p$ $=.009$. All other differences are not significant. Also, the difference in mean age discrepancy is significant between current and former partners, $t(1253)=2.584, p=.010$. ${ }^{\mathrm{d}}$ For homicides with women victims, none of the differences in mean age discrepancy is significant. For example, for spouse versus common-law, $t(552,=1.857, n s$; for spouse versus boyfriend/girlfriend, $t(579)=.984, n s$. Also, the difference in mean age discrepancy between current and former partners is not significant, $t(1320)=-1.238, n s$.

where the woman killed the man [4.41 versus $1.44, t(1253)=2.58, p=.010$ ], but not for homicides where the man killed the woman or for all homicides taken together. The man was at least 13 years older than the woman in $16.1 \%$ of the 1,183 homicides of a man by a woman current partner, versus $6.9 \%$ of the 72 homicides of a man by a woman former partner; the woman was at least 13 years older than the man in $2.8 \%$ of the current partner homicides versus $4.2 \%$ of the former partner homicides. Therefore, any association between age discrepancy and intimate relationship seems to be limited to homicides of men by women, and then occurs not by type of relationship but only by current versus former relationships.

There is little difference across racial/ethnic group in mean age discrepancy, 3.68 ( $S D=$ 9.12) for couples with a non-Latino White victim, $3.76(S D=9.41)$ for non-Latino Black, $3.30(S D=8.77)$ for Latino, and $2.89(S D=10.47)$ for Asian or other. None of these differences is significant (e.g., non-Latino White versus non-Latino Black, $t(2,408)=.006$, 
$n s$; non-Latino White versus Latino, $t(517)=.501, n s$; non-Latino White versus Asian or Other, $t(404)=.473, n s$ ). Additional analyses (available from the second author upon request) indicate few and nonpatterned effects of race/ethnicity on any of the target variables and, therefore, we do not discuss race/ethnicity further.

The Chicago Homicide Dataset encompasses a long time period, during which the level of intimate partner homicide declined (see Block \& Christakos, 1995; Greenfield et al., 1998; Paulozzi et al., 2001). Among the homicides under consideration in this analysis, the decade from 1965 to 1974 saw an average 54.3 men and 53.6 women killed per year, compared to 37.3 and 39.5 in the years 1975 to $1984,31.1$ and 33.3 in the years 1985 to 1994, and only 14.0 and 29.0 per year in 1995 and 1996. However, couple age discrepancy appears to vary randomly over time. The highest mean age discrepancy in any year from 1965 to 1996, 5.87, occurred in 1984, and the lowest, 0.43, occurred in 1981. The mean couple age discrepancy was 3.73 in the decade from 1965 to 1974, 3.55 from 1975 to $1984,3.96$ from 1985 to 1994 , and 2.99 in 1995 and 1996. None of these comparisons is statistically significant (all $t \mathrm{~s}<1.20$, all $p \mathrm{~s}>.05$ ).

The analysis of the offender's arrest record excluded an additional 88 cases for which prior arrest data were not available, leaving 2,489 cases for analysis. Most of these missing cases occurred in 1965, when the information was not recorded in the Murder Analysis Reports of the Chicago Police Department. Because there is a sharp and significant difference by sex $\left(\chi^{2}\right.$ $=206.39, d f=3, p<.001$ ) in the likelihood that the offender has a prior arrest record (see Table 5), this analysis was conducted separately for homicides with men or women offenders.

In general, there is no relationship between the homicide offender's absolute age and whether he or she has a prior record. The mean age of women offenders is 34.4 for women with a prior record and 33.6 for women without a record $(t=1.276, d f=1216, n s)$. The mean age of men offenders is 36.2 for men with a prior record and 39.8 for men without a record $(t=-4.939, d f=1271, p<.001)$, but this difference is due entirely to men who are age 50 or older. For men age 49 or younger, the mean age is almost identical for those who have a prior record (33.1) and those who do not (33.4) $(t=-.635, d f=1059, n s)$. While $67 \%$ of the 713 men offenders age 49 or younger have a prior record, only $51 \%$ of the 109 men offenders age 50 or older have a prior record, and $21 \%$ of the 24 men age 70 or older. Thus, among men who commit intimate partner homicide, men age 50 or older are less likely to have a prior record than younger men.

There is a significant association between age discrepancy and offender's prior record if the offender is a woman $\left(\chi^{2}=44.92, d f=13, p<.001\right)$, but not if the offender is a man $\left(\chi^{2}=11.96, d f=13, n s\right)$. Of the 302 women offenders who were older than their partner, $45 \%$ had a prior record, compared to $25 \%$ of the 113 who were the same age, and $34 \%$ of the 803 who were younger. The women offenders most likely to have a prior record (71\%)

TABLE 5. Prior Record of Intimate Partner Offender

\begin{tabular}{lcc}
\hline \multirow{2}{*}{ Prior Arrest Record, by Type } & \multicolumn{2}{c}{ Sex of Offender } \\
\hline No adult record & 63.8 & \% Man \\
Record, violent & 20.6 & 35.4 \\
Record, nonviolent & 13.3 & 41.5 \\
Record, type missing & 2.3 & 19.8 \\
\hline Total & 100.0 & 3.3 \\
& $(N=1,218)$ & 100.0 \\
& & $(N=1,271)$ \\
\hline
\end{tabular}


were women 13 to 15 years older than the man. Dividing the homicides according to the gender of offender and the offender's prior record results in small numbers in a few crosscategory cells (Table 6). Although these small numbers represent the population and not a sample of Chicago homicides in the given category, the resulting analysis should still be interpreted with caution.

\section{Population Data}

To calculate homicide rates across categories of partner age discrepancy, we need population data for those same categories. Census data for Chicago intimate relationships by partner age discrepancy are not publicly available (as per author communications with personnel at the U.S. Census Bureau, the City of Chicago Department of Public Health, and the Chicago Research Data Center). Even if census data on partner age discrepancy by marital status were available, marital status data would not be appropriate for these calculations. The intimate partner committing a homicide is not necessarily the person indicated by the victim's "marital status" (see Bachman \& Saltzman, 1995; Rennison, 2001; Schwartz, 1988). For example, a Chicago study of 699 women currently experiencing intimate partner violence (Block, 2000 a) found that $11 \%$ of abused women who reported their marital status as "married" were being abused by someone other than a current husband, $67 \%$ of women who said they were "separated" were being abused by someone other than a current or former husband, and $81 \%$ of women who said they were "divorced" were being abused by someone other than a former husband. This other abuser might be, for example, another boyfriend, a former intimate partner, or a current same-sex partner-19\% of the women who were being abused by a

TABLE 6. Number of Cases: Intimate Partner Homicides by Offender's Sex and Prior Record $(N=2,489)^{a}$

\begin{tabular}{lcccc}
\hline & $\begin{array}{c}\text { Male } \\
\text { Offender, } \\
\text { Prior } \\
\text { Record }\end{array}$ & $\begin{array}{c}\text { Male } \\
\text { Offender, } \\
\text { No Prior } \\
\text { Record }\end{array}$ & $\begin{array}{c}\text { Female } \\
\text { Offender, } \\
\text { Prior } \\
\text { Record }\end{array}$ & $\begin{array}{c}\text { Female } \\
\text { Offender, } \\
\text { No Prior } \\
\text { Record }\end{array}$ \\
Couple Age Discrepancy & & & & \\
Woman & 27 & 8 & 4 & 7 \\
More than 15 years older & 16 & 5 & 17 & 7 \\
13-15 years older & 27 & 8 & 11 & 13 \\
10-12 years older & 28 & 13 & 27 & 24 \\
7-9 years older & 60 & 28 & 23 & 40 \\
4-6 years older & 89 & 45 & 55 & 74 \\
1-3 years older & 59 & 37 & 28 & 85 \\
Same age & & & & \\
Man & 164 & 97 & 69 & 181 \\
1-3 years older & 114 & 72 & 50 & 112 \\
4-6 years older & 75 & 54 & 45 & 78 \\
7-9 years older & 59 & 27 & 28 & 49 \\
10-12 years older & 36 & 17 & 27 & 37 \\
13-15 years older & 37 & 22 & 21 & 33 \\
16-20 years older & 30 & 17 & 36 & 37 \\
More than 20 years older & 821 & 450 & 441 & 777 \\
Total & & & & \\
\hline
\end{tabular}

aThe 88 cases where the offender's prior record is not known have been excluded from this table. 
same-sex intimate partner reported that they were married, separated, or divorced. This lack of correlation between marital status and relationship indicates that marital status might be a poor metric to use for the population of people potentially at risk for heterosexual IPH.

To estimate populations for the 14 categories of partner age discrepancy, we applied age discrepancy proportions from the Chicago Women's Health Risk Study (Block, 2000a, 2000b) to the population of women aged 18 years and older in Chicago in 1980 (Table 7). In addition, we replicated our findings with similar population estimates based on 1970 and 1990 census data (U.S. Census Bureau Population Division, 1970, 1990). We could not locate population estimates for Chicago women 18 years and older in an intimate relationship in the preceding 12 months (see above), but justify use of the total population of women 18 years and older given that most women in this age group will have been involved in some type of intimate relationship in the preceding 12 months (see, e.g., Buss, 2004). We calculated annualized rates by dividing the average frequency of homicides per year in each age discrepancy category by the relevant population estimate for each age discrepancy category, and then multiplying this quotient by 100,000 . The resulting rates represent the number of homicides per year per 100,000 couples within each of 14 age discrepancy categories.

The Chicago Women's Health Risk Study (CWHRS) dataset includes data provided by 705 Chicago women who were at least 18 years of age and had been in an intimate relationship in the past 12 months at the time of the initial interview (July 1997 to September 1998). All women entering clinics at three medical centers (Cook County Hospital,

TABLE 7. Calculation of Age Discrepancy Population Estimates

\begin{tabular}{|c|c|c|c|}
\hline \multirow[b]{2}{*}{ Type of Age Discrepancy } & \multicolumn{2}{|c|}{ CWHRS Data ${ }^{\mathrm{a}}$} & \multirow{2}{*}{$\begin{array}{l}\text { Estimated } \\
\text { Population }^{\mathrm{b}}\end{array}$} \\
\hline & $N$ & $\%$ & \\
\hline \multicolumn{4}{|l|}{ Woman } \\
\hline More than 15 years older than man & 4 & 0.59 & $6,860.0$ \\
\hline 13 to 15 years older than man & 5 & 0.74 & $8,575.0$ \\
\hline 10 to 12 years older than man & 7 & 1.04 & $12,005.0$ \\
\hline 7 to 9 years older than man & 18 & 2.67 & $30,870.0$ \\
\hline 4 to 6 years older than man & 31 & 4.60 & $53,165.0$ \\
\hline 1 to 3 years older than man & 87 & 12.91 & $149,205.1$ \\
\hline Woman and man the same age & 77 & 11.42 & $132,055.1$ \\
\hline \multicolumn{4}{|l|}{ Man } \\
\hline 1 to 3 years older than woman & 164 & 24.33 & $281,260.2$ \\
\hline 4 to 6 years older than woman & 122 & 18.10 & $209,230.2$ \\
\hline 7 to 9 years older than woman & 66 & 9.79 & $113,190.1$ \\
\hline 10 to 12 years older than woman & 42 & 6.23 & $72,030.1$ \\
\hline 13 to 15 years older than woman & 27 & 4.01 & $46,305.0$ \\
\hline 16 to 20 years older than woman & 9 & 1.34 & $15,373.6$ \\
\hline More than 20 years older than woman & 15 & 2.23 & $25,661.2$ \\
\hline Total & 674 & 100.00 & $1,155,911$ \\
\hline
\end{tabular}

aAdapted from The Chicago Women's Health Risk Study, by C. R. Block, 2000, Chicago: Illinois Criminal Justice Information Authority. Excludes nine cases in which the man's age was not known.

bPopulation estimates were calculated by applying the proportion of couples in each age discrepancy category in the CWHRS (Block, 2000b) to 1,155,911, which is the total population of women, 18 years and older, in Chicago in the 1980 census (U.S. Census Bureau, 1980). Estimates for 1970 and 1990 are available on request to the second author. 
Roseland Public Health Clinic, and Erie Family Health Center) were screened as they entered the facility for any reason (e.g., well baby checkup, trauma from a car accident, prenatal checkup). The sample sites were selected because they are located in areas of the city with the highest rates of IPH. To estimate populations for the current study, we included only the 674 women whose relationship was with a male partner and the age of the partner was known. Because there was no significant difference $[t(672)<1.00, p>.05]$ in mean couple age discrepancy between women who had experienced violent abuse in the past year and women who had not, we combined the two groups.

The women in the CWHRS study comprise an approximately representative sample of all women 18 years and older who have been in an opposite sex intimate relationship recently and who reside in Chicago neighborhoods where the risk of IPH is high. Although the CWHRS is not a representative sample of women in the city as a whole, it is reasonable to consider it comparable to women at risk of becoming either the victim or the offender in a Chicago intimate partner homicide. Age discrepancy parameters are similar for the CWHRS and the Chicago Homicide Dataset. The average age of the 674 CWHRS women is 31.25 years $(S D=9.6)$, ranging from 18 to 67 years. The average age of the woman's male partner is 34.45 years $(S D=10.9)$, ranging from 16 to 73 years. The average age discrepancy between the intimate partners, calculated as the man's age minus the woman's age, is 3.2 years $(S D=6.7)$, and ranges from the woman being 20 years older than the man to the man being 42 years older than the woman.

\section{RESULTS}

\section{Partner Age Discrepancy and Risk of IPH}

The results indicate that the population-based risk of IPH victimization is substantially elevated for couples with a large age discrepancy (Figure 1). This supports the first hypothesis, and replicates the results of studies examining only cohabiting legal spouses or common-law spouses in national United States and Canadian data (e.g., Daly \& Wilson, 1988; Mercy \& Saltzman, 1989; Shackelford, 2000, 2001a, 2001b; Shackelford et al., 2000; Wilson \& Daly, 1992, 1994; Wilson et al., 1993, 1995). The rate of IPH for couples in which the woman is 16 or more years older than the man (21.41 per 100,000 couples per year) was four times higher than for couples with no age difference $(5.25$ per 100,000 couples per year). Similarly, the rate of intimate partner homicide for couples in which the man is 16 to 20 years older than the woman (23.99 per 100,000 couples per year) was four and a half times higher than for couples with no age difference. Thus, couples with large age discrepancies are overrepresented among IPHs in Chicago, compared to what would be expected from their numbers in the population.

We considered whether the lower homicide risk for couples where the man is 21 or more years older than the woman (14.86 per 100,000 couples per year), compared to couples where the man is 16 to 20 years older, might be explained by small and unreliable population figures at the extreme. However, that does not appear to be the case. When IPH risk was recalculated using "man 16 to 25 years older" and "man 26 or more years older" as the two extreme groups, the change in IPH rates was not relevant.

Because we were concerned that the lack of distinction between the different types of intimate relationship might affect the results, we conducted a separate analysis for married couples only. To calculate this analysis we needed the number of married 


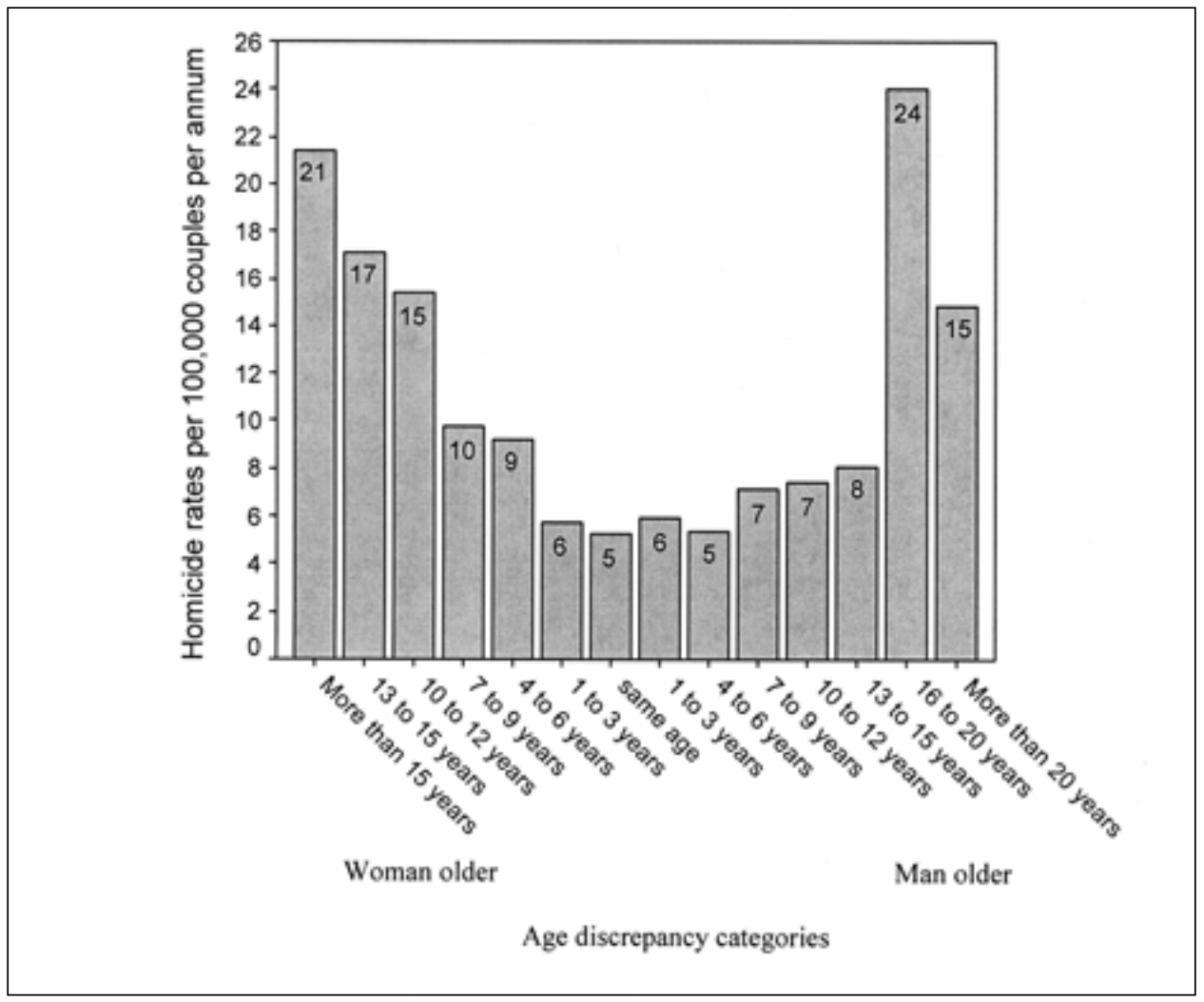

Figure 1. Intimate partner homicide risk is highest for age-discrepant couples. $N=2,577$. Adapted from Homicides in Chicago, 1965-1996, by C. R. Block and R. L. Block, 2003, Chicago: Illinois Criminal Justice Information Authority.

women in each age discrepancy category. This particular information is not publicly available, but the Census Bureau provided us the number of married woman 20 years and older in Chicago for the year 2000. Using this number and the proportion of married woman 20 years and older in the CWHRS in each age category, we calculated the population estimates. We then calculated the rates by dividing the number of IPHs involving married couples in each age discrepancy category of the Chicago Homicide Dataset by the corresponding population estimates, and multiplying that number by 100,000 population. The results of this analysis continue to show the U-shaped pattern, with especially elevated rates for married couples where the man is 16 to 20 years older (33.8) or the woman is 4 to 6 years older (20.5), compared to married couples who are the same age (4.8), although the rates for greater age discrepancy categories are unclear due to small numbers. ${ }^{3}$

The results in Figure 1 are based on an aggregate analysis of all homicide cases across the 32 years from 1965 to 1996 , divided by 32 to estimate the number per annum, and then divided by the estimated population of couples with a given age discrepancy in 1980. This aggregate analysis, centered on the 1980 census year, utilizes the greater precision offered by larger numbers. Although couple age discrepancy appears to vary randomly over time (see above), we were still concerned that population change might affect the results. Therefore, we conducted three separate analyses, for the periods from 1965 to 1974, 1975 


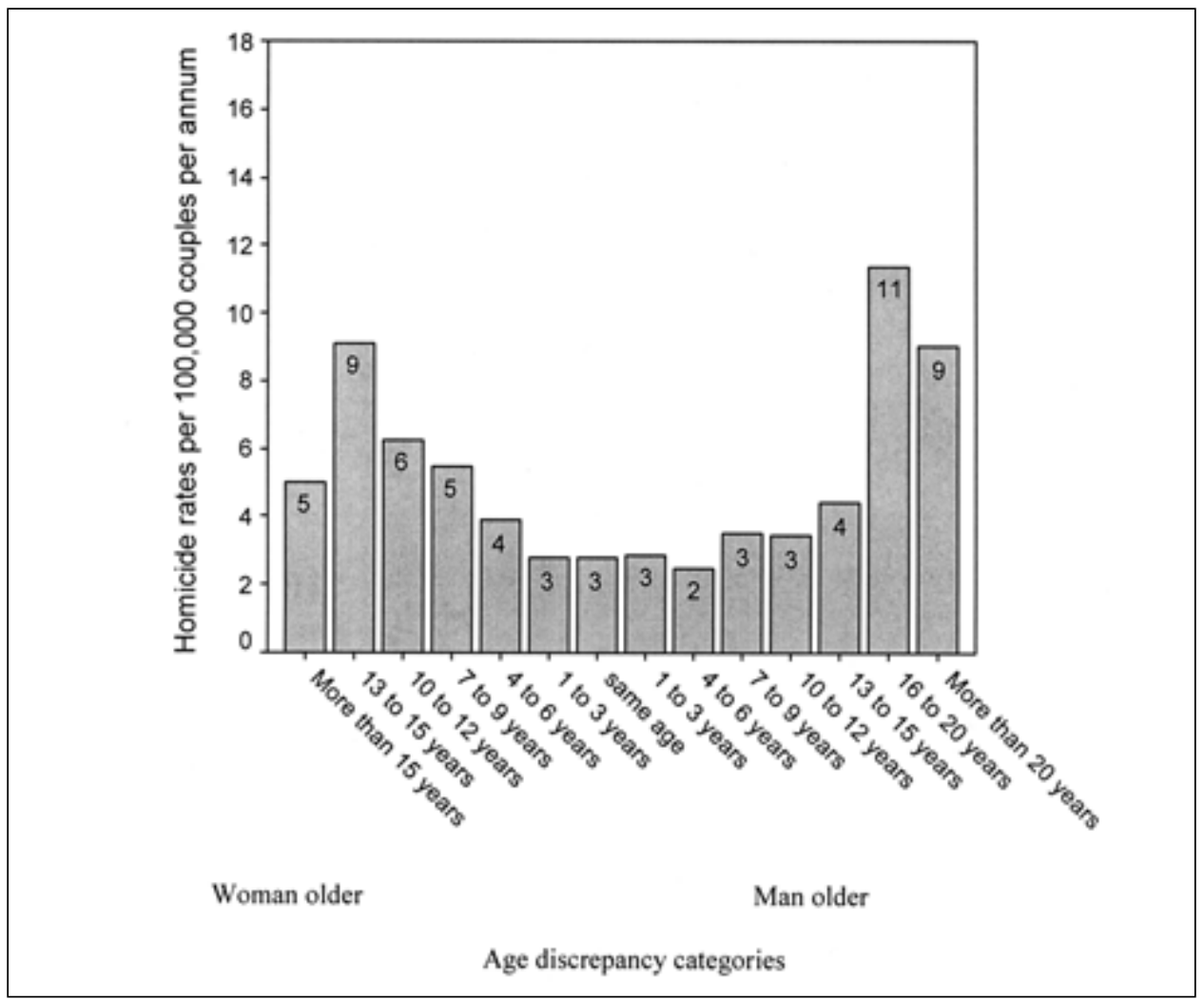

Figure 2. Intimate partner homicides committed by women. $N=1,255$. Adapted from Homicides in Chicago, 1965-1996, by C. R. Block and R. L. Block, 2003, Chicago: Illinois Criminal Justice Information Authority.

to 1984 , and 1985 to 1996 , centered on the census years 1970,1980 , and 1990 , respectively. The age discrepancy/homicide risk findings followed the same pattern within each of these three time periods as for the analysis of the entire 32 years. ${ }^{4}$

\section{Controlling for Offender's Sex}

Whether the woman kills the man (Figure 2) or the man kills the woman (Figure 3), the risk of intimate partner homicide is higher for couples with extreme age discrepancy than for couples whose partners are closer in age. The risk per 100,000 couples for womanoffender homicide (Figure 2) is highest when the man is older than the woman by more than 15 years ( 11.38 when the man is 16 to 20 years older; 9.01 when the man is more than 20 years older) or when the woman is older than the man by 13 to 15 years $(9.11)$. The risk of woman-offender homicide for same-age couples is only 2.79 per 100,000 couples per year. In the case of man-offender homicide (Figure 3), the risk per 100,000 couples per year is highest when the man is older by 16 to 20 years (12.6) or the woman is older by 10 or more years ( 9.11 when the woman is 10 to 12 years older; 8.02 when the woman is 13 to 15 years older; 16.4 when the woman is more than 15 years older); the risk is lowest for same-age couples (2.46). Although the absolute risk levels differ in Figure 2 and Figure 3, the similar U-shaped pattern indicates that the risk of IPH as a function of the partners' age discrepancy is not affected by the sex of the offender. 


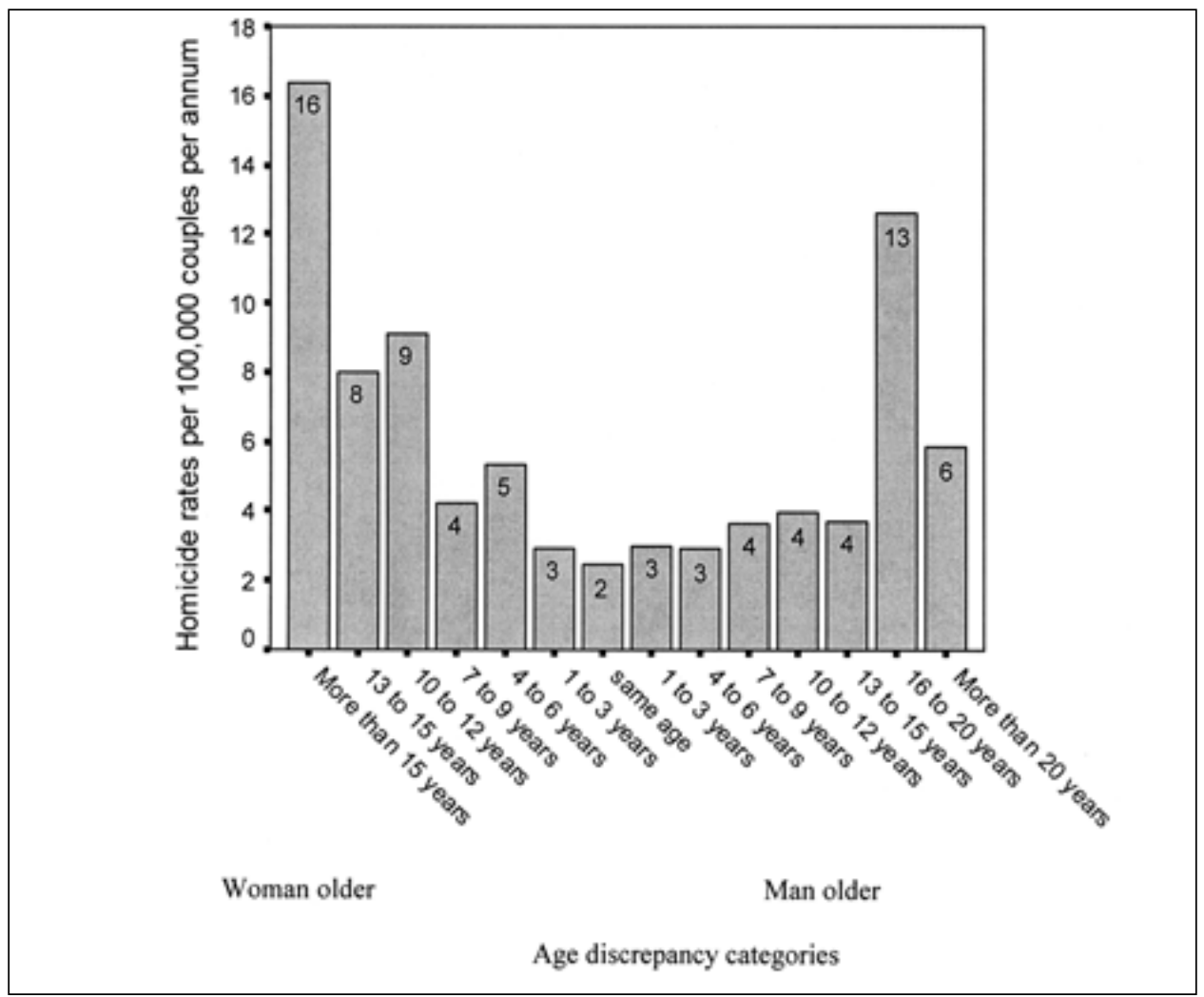

Figure 3. Intimate partner homicides committed by men. $N=1,322$. Adapted from Homicides in Chicago, 1965-1996, by C. R. Block and R. L. Block, 2003, Chicago: Illinois Criminal Justice Information Authority.

\section{Controlling for Previous Arrest Record}

Regardless of whether the offender (man or woman) has a previous arrest record, the IPH risk is higher for extreme age-discrepant couples, compared to couples with more similar ages. Figures 4 through 7 show population-based rates of IPH committed by men and women with and without previous arrest records. See Table 6 for the number of cases in each age discrepancy category, noting that 6 of the 84 categories have fewer than 10 cases. Although the level of IPH risk varies across the four figures, each of them shows the characteristic U-shaped pattern.

The risk per 100,000 couples per year of IPH by a male offender with a previous arrest record (Figure 4) is considerably higher when the woman is 10 or more years older than the man ( 7.03 when the woman is 10 to 12 years older; 5.83 when the woman is 13 to 15 years older; 12.3 when the woman is more than 15 years older) or when the man is 16 to 20 years older than the woman (7.52). The homicide risk for the 27 couples in which the woman is more than 15 years older is almost nine times that for the 59 couples who are the same age (1.4 per 100,000 couples per year). The risk per 100,000 couples per year of IPH by a male offender with no a previous arrest record (Figure 5) is highest when the man is 16 to 20 years older than the woman (4.47) or when the woman is 16 or more years older than the man (3.64), while the risk for same-age couples is only 0.88 . The risk per 100,000 couples per year of IPH by a woman offender with a previous arrest record (Figure 6) is highest when the man is 16 or more 


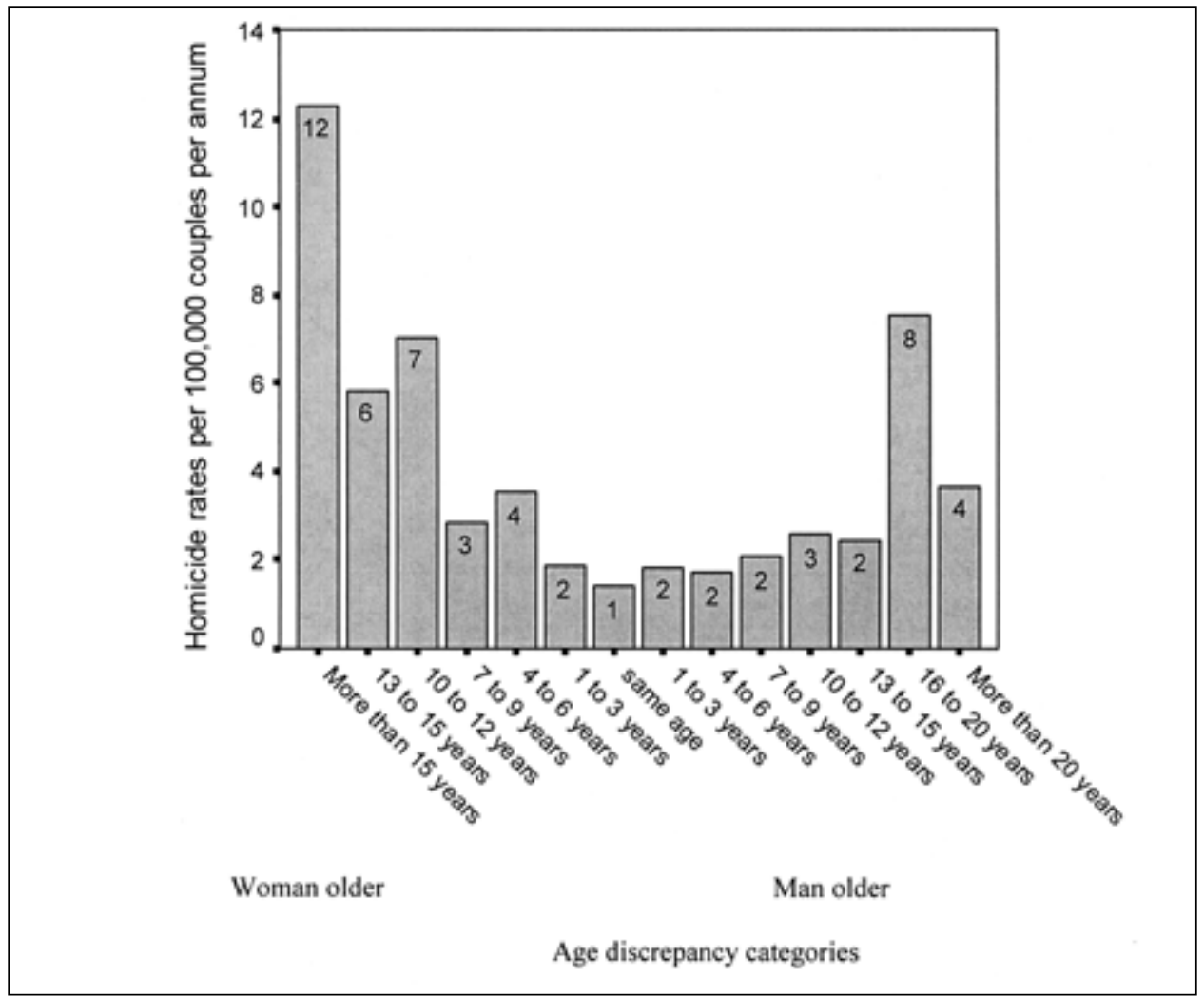

Figure 4. Intimate partner homicides committed by men with previous arrest records. $N=821$. Adapted from Homicides in Chicago, 1965-1996, by C. R. Block and R. L. Block, 2003, Chicago: Illinois Criminal Justice Information Authority.

years older than the woman ( 4.27 when the man is 16 to 20 years older; 4.38 when the man is more than 20 years older) or when the woman is 13 to 15 years older than the man (6.2). The risk of homicide by a woman offender with a previous arrest record is almost nine times higher for the 17 couples where the woman is 13 to 15 years older than the man than for the 28 couples who are the same age ( 0.66 per 100,000 couples per year). Finally, the risk of IPH by a woman with no previous arrest record (Figure 7) is highest when the man is at least 16 years older than the woman (6.71 per 100,000 couples per year) and is lowest when the woman is older than the man by 1 to 3 years ( 1.55 per 100,000 couples per year).

\section{SUMMARY}

Patterns of population-based rates of heterosexual intimate partner homicide for couples across 14 categories of couple age discrepancy support the hypothesis that the risk of IPH is elevated for couples with a large discrepancy between their ages. Separate analyses for IPH committed by men and by women support the hypothesis that the pattern is robust for both types of homicide. However, analysis controlling for the homicide offender's prior arrest record did not reduce or eliminate the association between the couple's age discrepancy and risk of IPH, thus, not supporting the hypothesis that the offender's previous 


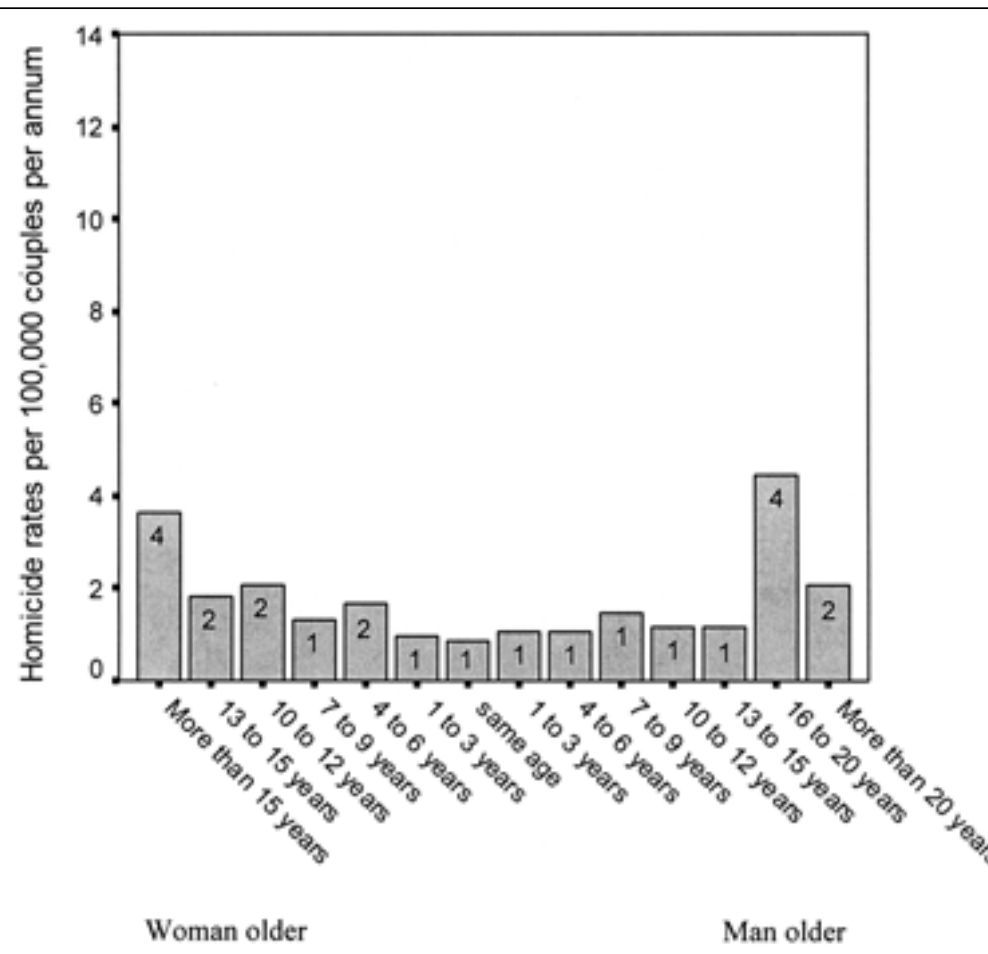

Age discrepancy categories ${ }^{\mathrm{a}}$

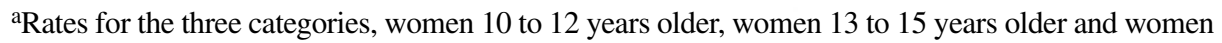
more than 15 years older, are based on fewer than 10 cases $(8,5$, and 8 , respectively); see Table 6 .

Figure 5. Intimate partner homicides committed by men without previous arrest records. $N=450$. Adapted from Homicides in Chicago, 1965-1996, by C. R. Block and R. L. Block, 2003, Chicago: Illinois Criminal Justice Information Authority.

arrest record would explain the association between age discrepancy and homicide risk. The U-shaped age discrepancy pattern appears to be robust, not only for homicides committed by men and women, but also for homicides committed by offenders with or without a prior arrest record. The pattern remains the same under both conditions.

\section{DISCUSSION AND CONCLUSIONS}

Although it has been 15 years since age discrepancy was identified as a predictor of intimate partner homicide (Daly \& Wilson, 1988), to date no research has addressed why couples with large age discrepancy are at greater risk. This study first documents that the association between extreme age discrepancy and elevated homicide risk occurs among all heterosexual intimate couples, not only cohabiting married or common-law couples. Using a Chicago dataset that includes all heterosexual intimate partner homicides, this analysis replicates national level findings for cohabiting legal spouses and common-law spouses (Mercy \& Saltzman, 1989; Shackelford, 2000, 2001a, 2001b; Shackelford et al., 2000). Specifically, couples in which the woman is older by at least 10 years or in which the man is older by at least 16 years have substantially higher risk of IPH, compared to 


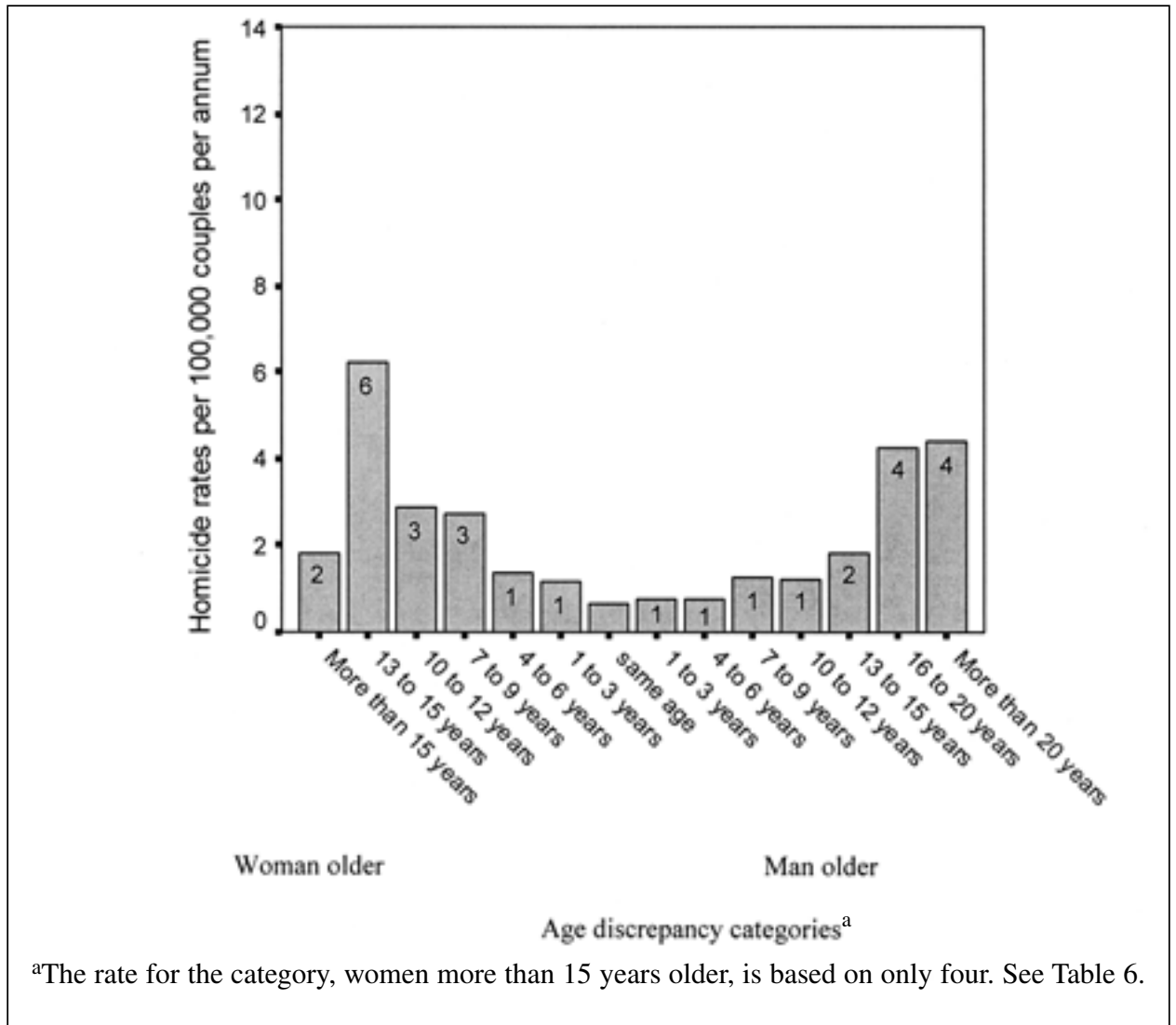

Figure 6. Intimate partner homicides committed by women with previous arrest records. $N=441$. Adapted from Homicides in Chicago, 1965-1996, by C. R. Block and R. L. Block, 2003, Chicago: Illinois Criminal Justice Information Authority.

more age-similar couples. The study then determines that the association is not affected by the sex of the offender. It then tests a hypothesis that leading researchers in the field since 1988 have put forth as a possible explanation: that people in marked age-discrepant relationships are not at an increased risk of IPH due to the direct effect of age discrepancy, but that people who have partners who are much older or much younger than themselves are more likely to be involved in all sorts of crime. Results show that, to the contrary, the increased risk of IPH in couples with large age discrepancy is not affected by the offender's previous arrest history.

This analysis addresses two limitations of previous research-first, that they did not include all types of intimate partner relationship, in particular those that may have high risk of intimate partner homicide, and second, that they did not contain enough detail to determine the mechanisms by which age discrepancy and homicide risk may be related. However, other limitations may still affect our results. First, given that homicides among intimate partners is a rare phenomenon, especially within the categories of couple age discrepancy, the accuracy of the population estimates for the 14 categories is paramount. Since Chicago census data by intimate relationship and partner age discrepancy are not publicly available, we calculated population estimates using age discrepancy proportions obtained by the CWHRS. Though the CWHRS is not a representative sample of all 


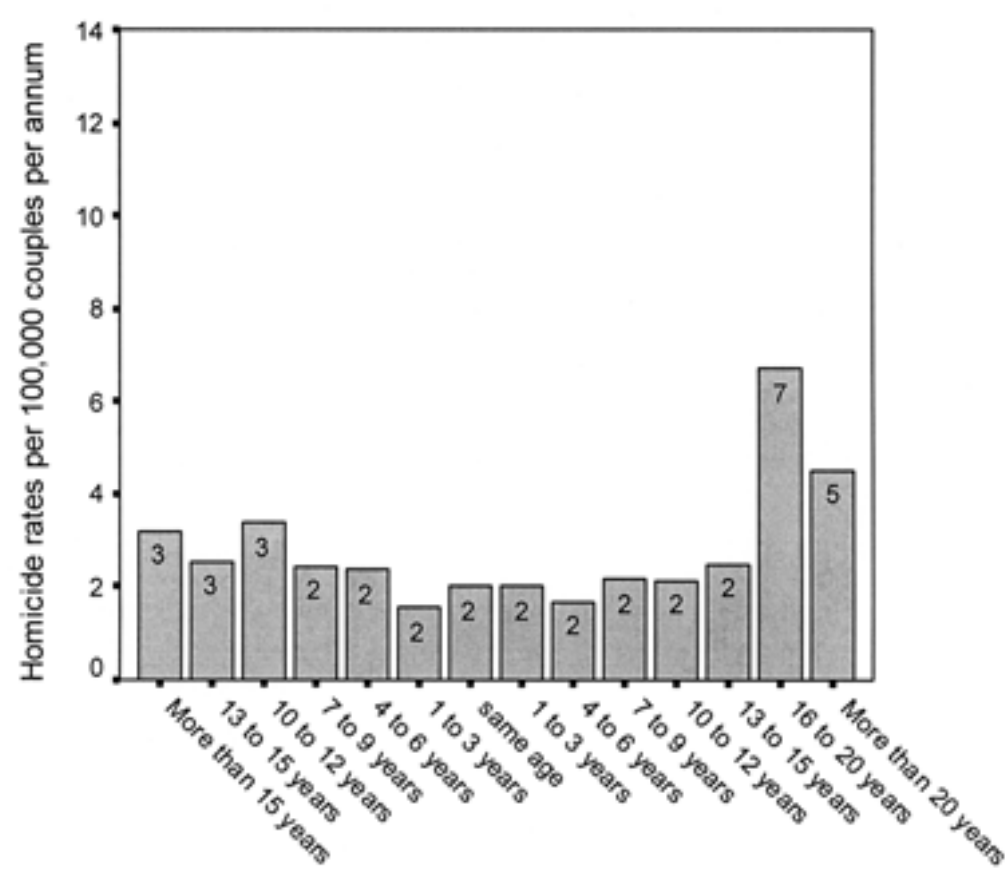

Woman older

Man older

Age discrepancy categories ${ }^{\text {a }}$

aRates for the two categories, women 10 to 12 years older and women 13 to 15 years older, are based on fewer than 10 cases ( 7 cases each); see Table 6.

Figure 7. Intimate partner homicides committed by women without previous arrest records. $N=777$. Adapted from Homicides in Chicago, 1965-1996, by C. R. Block and R. L. Block, 2003, Chicago: Illinois Criminal Justice Information Authority.

Chicago women, the sample selection procedures and data parameters indicate that it is reasonably comparable to women at risk of becoming either the victim or the offender in Chicago intimate partner homicides. Still, if they were available, the application of exact population figures would improve the credibility of the results. Second, the analysis is based on data aggregated across more than 30 years, a period seeing changes in both intimate partner homicide levels and Chicago population characteristics. To address this concern, we conducted replications of the analysis for two other census years (1970 and 1990), and found that the results followed the familiar U-shaped pattern. Third, we were concerned that the broad definition of intimate partners could affect the results, but a separate analysis of the homicide risk for married couples showed similar results. Fourth, we were concerned that the absolute age of offender or victim might be confounding the results. The individual's age is associated with risk of IPH victimization and offending, and there is no way to separate absolute age from age discrepancy at the extremes. However, if the entire association between age discrepancy and IPH risk were due to absolute age, then we would not expect to see the same effects when the woman versus the man is the offender. The consistency of the U-shaped pattern under all conditions argues against the effect being an artifact of absolute age. 
In addition, we were not able to examine the robustness of the age discrepancy-homicide risk association under certain conditions, due to the small number of cases in each age discrepancy category. For instance, we found a significantly different mean age discrepancy for man-offender and woman-offender homicides with a non-Latino White victim, but were unable to run a separate analysis by racial/ethnic group. We also found a significant difference in the mean age discrepancy for current and former relationships, but the small number of cases in each category and the absence of population data made it impossible to run a separate analysis by current versus former relationship.

Because all the additional analyses conducted to check for accuracy consistently produced the familiar U-shaped pattern, we conclude that two things can be said with relative confidence about partner age discrepancy and intimate partner homicide. First, the risk of homicide is high, relative to the population, for intimate heterosexual couples where one partner is many years older than the other. Second, the elevated risk cannot be "explained away" by controlling for the offender's sex or the offender's arrest record. All this, however, still does not tell us why high age discrepancy between intimate partners is associated with greater risk of lethal violence. If domestic violence advocates or other helping professionals are to use these results as a basis for clinical decisions, it is vital to answer this question.

One possibility is that partner age discrepancy has a direct effect on lethal violence between partners. For example, perhaps partners who are widely different in age also are more likely to be widely different in physical strength and vulnerability, and the victim of an assault is therefore more likely to die. The research of $\mathrm{Wu}$ and colleagues $(\mathrm{Wu} \&$ Balakrishnan, 1995; Wu \& Hart, 2001) suggests another scenario-that partner age discrepancy is only one aspect of partner heterogeneity and that heterogeneity has fundamental effects on stress in the relationship. Though the Wu research does not look at partner violence, it is reasonable to hypothesize that violence could be one outcome of increased stress. A third possibility, seen in a few of the CWHRS homicides, occurs when one partner plans to kill the other, with an eye toward monetary gain. Are such homicides more likely with greater age discrepancy? The answers to these questions must await further research.

Alternatively, a couple's age discrepancy may not be related directly to lethal violence, but indirectly, via some other factor or factors that, in turn, are risk factors for IPH. Although this analysis has determined that prior arrest record does not explain the Ushaped pattern, there may be other variables to consider. For example, couples with high age discrepancy may also have higher levels of sexual jealousy and proprietariness, a characteristic found in many studies to be a risk factor for intimate partner homicide (see for example, Block, 2000a; Campbell, 1992; Smith, 1990; Wilson \& Daly, 1992b). Also, partners with greater age discrepancy might be more likely to have stepchildren in the family, and the presence of stepchildren is related to the risk of lethal violence (see Daly, Wiseman, \& Wilson, 1997). Further research is needed to identify or eliminate any risk factor that might mediate between partner age discrepancy and the risk of IPH.

An additional consideration raised by these results is that, unlike most other factors associated with lethal intimate partner violence, age discrepancy does not appear to be associated with nonlethal intimate partner violence. When Wilson, Johnson, and Daly (1995) compared lethal to nonlethal risk patterns for violence against wives in Canada, the results indicated that many factors, such as male sexual proprietariness, type of marital union, recent separation, age of wife, and age of husband, were associated with both lethal and nonlethal violence against wives, but age discrepancy was associated only with lethal violence. Similarly, the Chicago Women's Health Risk Study found that partner age discrepancy patterns were the same for women experiencing nonlethal intimate partner 
violence and a comparison group of women not experiencing violence (Block, 2000a). If it is true that age discrepancy is related to lethal intimate partner violence but not related to nonlethal intimate partner violence, what could be the reason? Is there some attribute of age discrepancy that is related specifically to the fatality of assaults? Future research will have to deal with these questions.

\section{PRACTICAL IMPLICATIONS}

Although many questions remain to be answered, the current analyses of the Chicago Homicide Dataset represent first steps towards developing practical implications. Because we do not yet know why partner age discrepancy is associated with a higher risk of lethal violence, it is important to be cautious in applying this information to practical situations. There are many indications, however, that such an association does in fact exist. Therefore, practitioners should include age discrepancy in their list of risk factors for IPH. Specifically, practitioners might consider the following suggestions, based on the results of this research:

- Gather age information for both partners. Age information is simple and safe to gather. There is potential benefit and little risk or cost to asking people for this information. ${ }^{5}$

- Record the couple's age discrepancy with a notation for level of risk. Risk is substantially elevated when the man is at least 16 years older than the woman or the woman is at least 10 years older than the man.

- Use "elevated risk based on couple age discrepancy" in conjunction with other screening and assessment tools. For example, when discussing the results of the Campbell Danger Assessment (Campbell et al., 2000), tell women when her "couple age discrepancy" might further increase her risk. Do not integrate age discrepancy into a screening or assessment instrument until we know more about how it interacts with other couple characteristics.

- Consider women's victimization risk in light of the man's previous arrest record. The risk for a woman being killed is higher when her partner has a previous arrest record, regardless of the age discrepancy between them.

- Consider men's victimization risk in light of known risk factors for IPH by a woman offender. The CWHRS (Block, 2000a) found three factors to be associated with womanoffender IPH: severe and increasing intimate partner violence against the woman, few material resources, and a traditional and lengthy relationship.

\section{NOTES}

1. This is an expansion of the data currently archived in the National Archive of Criminal Justice Data (Block, Block, \& ICJIA, 1998). The Authority, working closely with the Chicago Police Department, is in the process of updating the Chicago Homicide Dataset through 2001.

2. In multiple offender or multiple victim homicides, we included in this analysis only the intimate partner victim-offender dyad. In total, there were 2,745 intimate partner homicides, of which 84 were same-sex.

3. These analyses are available from the second author upon request.

4. The separate analyses of these three time periods are available from the second author upon request.

5. For people in an abusive situation, practitioners should record the age of the abusive partner. That person may not be the current intimate partner. 


\section{REFERENCES}

Bachman, R., \& Saltzman, L. E. (1995). Violence against women: Estimates from the redesigned survey (Bureau of Justice Statistics Special Report, NCJ 154348). Washington, DC: U.S. Department of Justice.

Block, C. R. (1987). Lethal violence at home: Racial/ethnic differences in domestic homicide in Chicago, 1965-1981. Paper presented at the American Society of Criminology Annual Meeting, Montreal, Quebec, Canada.

Block, C. R. (2000a). The Chicago Women's Health Risk Study. Report to the National Institute of Justice. Chicago: Illinois Criminal Justice Information Authority.

Block, C. R. (2000b). The Chicago Women's Health Risk Study [Computer file]. Chicago: Illinois Criminal Justice Information Authority.

Block, C. R., Block, R. L., \& Illinois Criminal Justice Information Authority. (1998). Homicides in Chicago, 1965-1995 ([Computer file] 4th ICPSR version). Chicago: Illinois Criminal Justice Information Authority [producer]. Ann Arbor, MI: Inter-university Consortium for Political and Social Research [distributor].

Block, C. R., \& Block, R. L. (2001). Homicides in Chicago, 1965-1996 [Computer file]. Chicago: Illinois Criminal Justice Information Authority.

Block, C. R., \& Block, R. L. (2003). Homicides in Chicago, 1965-1996 [Computer file]. Chicago: Illinois Criminal Justice Information Authority.

Block, C. R., \& Christakos, A. (1995). Intimate partner homicide in Chicago over 29 years. Crime and Delinquency, 41, 496-526.

Boudouris, J. (1971). Homicide and the family. Journal of Marriage and the Family, 3, 667-676.

Buss, D. M. (2004). The evolution of desire (Rev. ed.). New York: Basic Books.

Campbell, J. C. (1992). "If I can't have you, no one can": Power and control in homicide of female partners. In J. Radford \& D. E. H. Russell (Eds.), Femicide (pp. 99-113). New York: Twayne.

Campbell, J. C., Sharps, P., \& Glass, N. (2000). Risk assessment for intimate partner homicide. In G. F. Pinard and L. Pagani (Eds.), Clinical assessment of dangerousness (pp. 136-157). New York: Cambridge University Press.

Daly, M., \& Wilson, M. (1988). Homicide. Hawthorne, NY: Aldine de Gruyter.

Dumas, J., \& Perón, Y. (1992). Marriage and conjugal life in Canada (No. 91-534E). Ottawa: Statistics Canada.

Greenfeld, L. A., Rand, M. R., Craven, D., et al. (1998). Violence by intimates: Analysis of data on crimes by current or former spouses, boyfriends, and girlfriends. In Bureau of Justice Statistics Factbook. Washington, DC: U.S. Department of Justice.

Johnson, H. (1996). Dangerous domains. Toronto: Nelson Canada.

Mercy, J., \& Saltzman, L. E. (1989). Fatal violence among spouses in the United States, 1976-85. American Journal of Public Health, 79, 595-599.

Paulozzi, L. J., Saltzman, L. E., Thompson, M. P., \& Holmgreen, P. (2001). Surveillance for homicide among intimate partners-United States, 1981-1998. Morbidity and Mortality Weekly Report (MMWR) Surveillance Summaries, 50 (SS03, October 12), 1-16.

Rennison, C. M. (2001). Intimate partner violence and age of victim, 1993-99 (Bureau of Justice Statistics Special Report, NCJ 187635). Washington, DC: U.S. Department of Justice.

Rennison, C. M., \& Welchans, S. (2000). Intimate partner violence (Bureau of Justice Statistics Special Report, NCJ 178247). Washington, DC: U.S. Department of Justice.

Saltzman, L. E., Fanslow, J. L., McMahon, P. M., \& Shelley, G. A. (1999). Intimate partner violence surveillance: Uniform definitions and recommended data elements (Version 1.0). Atlanta: U.S. Department of Health and Human Services, CDC.

Schwartz, M. D. (1988). Marital status and woman abuse theory. Journal of Family Violence, 3, 239-248.

Shackelford, T. K. (2000). Reproductive-age women are overrepresented among perpetrators of husband killing. Aggressive Behavior, 26, 309-317. 
Shackelford, T. K. (2001a). Cohabitation, marriage, and murder: Woman-killing by male romantic partners. Aggressive Behavior, 27, 284-291.

Shackelford, T. K. (2001b). Partner-killing by women in cohabiting relationships and marital relationships. Homicide Studies, 5, 253-266.

Shackelford, T. K., Buss, D. M., \& Peters, J. (2000). Wife killing: Risk to women as a function of age. Violence and Victims, 15, 273-282.

Smith, M. D. (1990). Patriarchal ideology and wife beating: A test of a feminist hypothesis. Violence and Victims, 3, 257-273.

U. S. Census Bureau Population Division. (1970). 1970 Census data. Washington, DC: Author.

U. S. Census Bureau Population Division. (1980). 1980 Census data. Washington, DC: Author

U. S. Census Bureau Population Division. (1990). 1990 Census data. Washington, DC: Author.

Wilson, M., \& Daly, M. (1992). Who kills whom in spouse killings? On the exceptional sex ratio of spousal homicides in the United States. Criminology, 30, 189-215.

Wilson, M., \& Daly, M. (1993). An evolutionary psychological perspective on male sexual proprietariness and violence against wives. Violence and Victims, 8, 271-294.

Wilson, M., \& Daly, M. (1994). Spousal homicide. Juristat, 14, 1-15.

Wilson, M., \& Daly, M. (1996). Male sexual proprietariness and violence against wives. Current Directions in Psychological Science, 5, 2-7.

Wilson, M., Daly, M., \& Wright, C. (1993). Uxoricide in Canada: Demographic risk patterns. Canadian Journal of Criminology, 35, 263-291.

Wilson, M., Johnson, H., \& Daly, M. (1995). Lethal and nonlethal violence against wives. Canadian Journal of Criminology, 37, 331-361.

Wilson, M., Daly, M., \& Daniele, A. (1995). Familicide: The killing of spouse and children. Aggressive Behavior, 21, 275-291.

Wu, Z., \& Balakrishnan, T. R. (1995). Dissolution of premarital cohabitation in Canada. Demography, 32, 521-532.

Wu, Z., \& Hart, R. (2001). Marital and nonmarital union separation in Canada. Paper presented at the International Union for Scientific Study of Population.

Acknowledgment. The Chicago Homicide Dataset is a collaborative project of the Chicago Police Department, the Illinois Criminal Justice Information Authority, and Loyola University, Chicago.

Offprints. Requests for offprints should be directed to Todd K. Shackelford, $\mathrm{PhD}$, Florida Atlantic University, Department of Psychology, 2912 College Avenue, Davie, FL 33314. E-mail: tshackel@fau.edu 